\title{
вмJ Global Health The impact of diabetes on the productivity and economy of Bangladesh
}

\author{
Afsana Afroz (D) , ${ }^{1}$ Thomas R Hird, ${ }^{1,2}$ Ella Zomer, ${ }^{1}$ Alice Owen, ${ }^{1}$ Lei Chen, ${ }^{2}$
} Zanfina Ademi (D) , ${ }^{1}$ Danny Liew, ${ }^{1}$ Dianna J Magliano, ${ }^{1,2}$ Baki Billah ${ }^{1}$

To cite: Afroz A, Hird TR, Zomer E, et al. The impact of diabetes on the productivity and economy of Bangladesh. BMJ Global Health 2020;5:e002420. doi:10.1136/ bmjgh-2020-002420

Handling editor Lei Si

Received 24 February 2020

Revised 2 May 2020

Accepted 6 May 2020
Check for updates

(C) Author(s) (or their employer(s)) 2020. Re-use permitted under CC BY-NC. No commercial re-use. See rights and permissions. Published by BMJ

${ }^{1}$ Department of Epidemiology and Preventive Medicine,

Monash University School of

Public Health and Preventive

Medicine, Melbourne, Victoria, Australia

2Diabetes and Population Health, Baker IDI Heart and Diabetes Institute, Melbourne, Victoria, Australia

Correspondence to

Dr Afsana Afroz;

afsana.afroz@monash.edu

\section{ABSTRACT}

Aims To estimate the impact of type 2 diabetes in terms of mortality, years of life lost (YLL) and productivityadjusted life years (PALY) lost in Bangladesh.

Methods A life table model was constructed to estimate the productivity of the Bangladeshi population of current working age (20-59 years) with diabetes. Follow-up to 60 years (retirement age) was simulated. The life table analysis was then repeated assuming that the cohort did not have diabetes, with subsequent improvement in productivity. Differences in the results of the two analyses reflected the impact of diabetes on health and productivity. Demographic and the prevalence of diabetes data were sourced from the International Diabetes Foundation estimates for 2017 and mortality data were based on the 2017 Global Burden of Disease study. Relative risk and productivity indices were based on an Indian and Bangladeshi study, respectively. The cost of each PALY was assumed to be equivalent to gross domestic product (GDP) per equivalent full-time worker (US\$8763). Future costs and years of life, and PALYs lived were discounted at an annual rate of $3 \%$.

Results Assuming a follow-up of this population (aged 20-59 years) until age 60 years or death, an estimated 813807 excess deaths, loss of 4.0 million life years $(5.5 \%)$ and 9.2 million PALYs (20.4\%) were attributable to having diabetes. This was equivalent to $0.7 \mathrm{YLL}$, and 1.6 PALYs lost per person. The loss in PALYs equated to a total of US $\$ 97.4$ billion lost (US\$16 987 per person) in GDP. The results of the scenario analysis showed that the estimation was robust.

Conclusion In Bangladesh, the impact of diabetes on productivity loss and the broader economy looms large, and poses a substantial risk to the country's future prosperity. This highlights the critical importance of health strategies aimed at the control of diabetes.

\section{INTRODUCTION}

Diabetes is a leading cause of morbidity and mortality across the globe. ${ }^{12}$ According to the International Diabetes Federation (IDF), the cluster of low to middle-income countries which make up South-East Asia is home to 88 million people (aged 20-79 years) living with diabetes. ${ }^{3}$ Mauritius has the highest $(22.0 \%)$

\section{Key questions}

What is already known?

- Diabetes places an enormous economic burden on the global population and also has significant impact on productivity.

- The impact of diabetes on work productivity has been addressed adequately in the context of highincome countries but there is a lack of studies in low and lower middle-income countries, which include Bangladesh.

\section{What are the new findings?}

- Using productivity-adjusted life years (PALY), we estimated that 9.2 million PALYs (20.4\%) were attributable to having diabetes. The loss in PALYs equated to a total of US\$97.4 billion lost (US\$16 987 per person) in gross domestic product.

- This highlights the critical importance of health strategies aimed at the control of diabetes in Bangladesh.

\section{What do the new findings imply?}

- This work demonstrates that diabetes prevention interventions are not just an opportunity to improve health outcomes for the Bangladeshi populace, but an imperative for future prosperity for the country.

age-adjusted diabetes prevalence in adults aged 20-79 years in the Region, followed by Sri Lanka $(10.7 \%)$ and India $(10.4 \%)$. Adults with diabetes in India, Bangladesh and Sri Lanka make up $98.9 \%$ of the total adult population with diabetes in this region. ${ }^{3}$ In Bangladesh, the prevalence of diabetes has been steadily rising, reaching 8.1 in 2019 and $63.4 \%$ of people with diabetes have diabetesrelated macrovascular and microvascular complications. ${ }^{3-5}$ Compounding the problem, compared with Caucasian populations, Asian populations experience more severe complications and greater risk of premature mortality. ${ }^{56}$ Furthermore, diabetes develops at an earlier age, meaning the absolute burden of disease is higher among younger populations in Asia. ${ }^{7}$ 
In addition to the direct (healthcare-related) costs of diabetes, the indirect costs are also significant. ${ }^{8}$ Indirect costs include work productivity losses, which can be measured through absenteeism (workday lost due to illness), presenteeism (impaired function at work due to illness) or labour force dropout (retirement before the official retirement age due to illness or premature death). ${ }^{9} 10$ The economic impact of productivity loss poses a burden to individuals, society and the country as a whole in terms of lost income earnings, tax revenue and reduced gross domestic product (GDP). ${ }^{11}$ In 2017, an estimated US $\$ 89.9$ billion was lost due to diabetes-related productivity losses in the USA, including diabetes-related absenteeism (US $\$ 3.3$ billion), presenteeism (US $\$ 26.9$ billion), reduced labour force participation (US\$37.5 billion) and diabetes-related premature deaths (US $\$ 19.9$ billion). ${ }^{11}$ In China, a total of $¥ 17.4$ trillion (US\$2.6 trillion) in lost GDP owing to reduced productivity, with an average of $¥ 307925$ (US\$45 959) lost per person with diabetes. ${ }^{13}$ In Bangladesh in 2017, diabetes was the eighth highest cause of death and disability in the country. ${ }^{14}$ Diabetes also costs Bangladesh approximately US $\$ 5.3$ billion in direct healthcare costs in $2014 .^{15}$

A number of studies have examined the impact of diabetes on work productivity loss in high and upper middle-income countries, ${ }^{13} 16$ but not in low and lower middle-income countries. This information will inform investment in strategies to control diabetes and its complications. Thus, the aim of this study was to estimate the health impact of diabetes in the context of years of life lost, productivity-adjusted life years (PALY) lost and their effect on $\mathrm{GDP}^{1617}$ in Bangladesh.

\section{RESEARCH DESIGN AND METHODS}

We used Microsoft Excel to assist us with curating life tables for the Bangladeshi population. Our analyses used multistate life table models, constructed for separate sex and age (in 5 years age group) cohorts of the Bangladeshi population aged 20-59 years in both men and women, with follow-up until 60 years (retirement age) ${ }^{18}$ with estimation of years of life and PALYs lived. First, a life table model was developed to estimate these parameters for the Bangladeshi population of working age with diabetes. Then, the cohort was resimulated with the hypothetical assumption that subjects did not have diabetes thereby improving mortality, labour force participation and relative productivity (see below). The differences between the two cohorts in terms of total years of life and PALYs lived reflect the impact of diabetes. The key model inputs and their data sources are shown in online supplementary EMS table 1. The WHO standard $3 \%$ annual discount rate was applied to all future years of life and PALYs lived. ${ }^{19}$

\section{Population and mortality rates}

The demographics of the model population were profiled using IDF estimates for 2017. ${ }^{4}$ Data regarding diabetes prevalence, stratified by sex and 5 years age group, were also derived from the 2017 IDF Diabetes Atlas. ${ }^{4}$ Sex and age-specific mortality data for 2017 were retrieved from the Institute for Health Metrics and Evaluation-Global Health Data Exchange database. ${ }^{20}$ Since there were no mortality rates in Bangladesh, age and sex-specific mortality data for 2017 were extrapolated from the Chennai Urban Rural Epidemiology Study-150. ${ }^{21}$ These were attributed to those with and without diabetes based on age and sex-specific diabetes prevalence and the relative risk of all-cause mortality associated with diabetes in Bangladeshi populations. Based on an assumption that the mortality rate for a 5 years age group applied to people in the midpoint of that age band, mortality rates for age in single years were derived using exponential functions (online supplimentary EMS table 2). Temporal trends in population mortality across the model time horizon were projected using the average annual proportional reduction in adult mortality in Bangladesh $(1.0 \%$ per year) from the United Nations World Population Prospects (UN WPP) forecast. ${ }^{22}$ Estimated annual age and sex-specific mortality rates were applied to the model in yearly cycles, with deaths assumed to have occurred at the midpoint of the year.

\section{Labour force participation}

Sex and age-specific labour force participation in Bangladesh was sourced from the International Labour Organization (ILO) estimates for $2017 .{ }^{23}$ Labour force participation was lowest in men aged $20-24$ years $(74.5 \%)$ and in women aged $55-59$ years $(30.7 \%)$. The participation was highest in men aged $30-34$ years $(97.9 \%)$ and in women aged $35-39$ years $(49.2 \%)$.

\section{Productivity indices}

Diabetes-related productivity loss was quantified in terms of productivity indices, which reflect relative work productivity impairment, and range from 0 (entirely unproductive) to 1 (entirely productive).$^{16} 17$ Productivity indices were derived from estimates of labour force participation and absenteeism in people with diabetes compared with those without. ${ }^{24}$ Diabetes-related labour force dropout was expressed as labour force participation percentage shortfall, and ranged from $7.0 \%$ in women and $5.2 \%$ in men with diabetes aged $20-29$ years to $12.8 \%$ in women and $8.3 \%$ in men with diabetes over 40 years. ${ }^{24}$ These relative reductions were applied to the 2017 ILO sex and age group-specific population labour force participation rates to estimate labour force participation in those with and without diabetes. All workers were assumed to be in equivalent full-time (EFT) employment due to the absence of data on division of the labour force into full and part-time employment.

To calculate the total number of PALYs lived by the cohorts, each year lived in the labour force was multiplied by a productivity index derived from estimates of diabetes-related absenteeism. ${ }^{16}$ Absenteeism was defined as the number of lost workdays per year due to 
diabetes and was expressed as a percentage of the total working days per year. These inputs were derived from primary data collected through a cross-sectional study in Bangladesh in $2017,{ }^{25}$ stratified by sex and 5 years age group. Absenteeism was estimated to be on average 4.1 and 4.9 days per year in men and women, respectively. These represented a loss of $1.7 \%$ and $2.0 \%$, respectively, of the 240 maximum working days per year in Bangladesh. Hence, the productivity indices for men and women with diabetes were 0.983 and 0.980 , respectively.

Data on GDP per worker in Bangladesh, drawn from the World Bank database for 2017, are estimated to be BDT701 062 (US\$8763) in 2017. ${ }^{26}$ As per other studies we assumed that the economic value of each PALY was equivalent to the annual GDP per worker,. ${ }^{16}$ We projected temporal trends in GDP across the model's time horizon using the Organisation for Economic Co-operation and Development (OECD) long-term GDP forecasts. ${ }^{27}$

\section{Scenario analyses}

First, the individual contribution of absenteeism, labour force dropout and premature mortality to productivity loss were calculated and considered as the base case. Second, to assess the impact of uncertainty around diabetes-related mortality risk, productivity indices and economic data inputs, deterministic sensitivity analyses were performed on the model to calculate PALYs lost in the Bangladeshi population with diabetes. These included using the upper and lower 95\% CIs around estimates of all-cause mortality associated with diabetes, ${ }^{28}$ and varying estimates of absenteeism and labour force dropout by $25 \% .^{24}$ Finally, scenario analyses were undertaken to explore other model assumptions: doubling the average annual reduction in mortality risk from the UN WPP ( $1.0 \%$ per year) to a $2 \%$ reduction per year; removing the temporal trend in mortality risk; doubling the annual GDP growth rate from $1.8 \%$ per year (OECD forecast average annual GDP growth rate) to $3.6 \%$ per year; removing the temporal trend in GDP per worker ${ }^{26}$; and varying the annual discount rate to $5 \%$ and $1.5 \% .^{19}$

\section{Patient and public involvement}

Patients or the public were not involved in the development or implementation of this study.

\section{RESULTS}

As estimated by the IDF, ${ }^{4}$ the prevalence of diabetes was $7.0 \%$ in women and $5.7 \%$ in men (table 1 ).

\section{Excess mortality and years of life lost to diabetes}

The projected deaths in each 5 years age group and sex group are shown in table 2. It was estimated that of the current working age population followed up until retirement, there were 813807 extra deaths due to diabetes (304 682 and 509125 among men and women, respectively). Over the modelled time horizon (over 40 years), 3.9 million years of life $(5.5 \%)$ would be lost to diabetes, which equated to overall 0.7 years (for both men and women) of life lost per person in the diabetes population.

\section{PALYs lost to diabetes}

It was estimated that 9.2 million (20.4\%) PALYs were lost due to diabetes, which equated to 1.6 PALYs lost per person (1.7 in men and 1.5 in women) (table 3 ). Assuming a constant GDP per EFT worker of BDT701 062 (US\$8763), the economic impact of productivity lost due to diabetes in Bangladesh would be BDT7.7 trillion (US $\$ 97.4$ billion) loss in GDP. This is equivalent to an average GDP loss of BDT1 358969 (US\$16 987) per person with diabetes over the working lifespan.

\section{Scenario analyses}

Figure 1 shows the contribution of labour force dropout, mortality and absenteeism to diabetes-related productivity loss. Labour force dropout $(64.9 \%)$ was the major contributor to productivity loss followed by mortality

Table 1 The age and gender-specific population and number of people living with diabetes in Bangladesh in 2017

\begin{tabular}{|c|c|c|c|c|c|c|}
\hline \multirow[b]{2}{*}{ Age group } & \multicolumn{3}{|l|}{ Men } & \multicolumn{3}{|l|}{ Women } \\
\hline & Population* & $\begin{array}{l}\text { Prevalence of } \\
\text { diabetes }(\%)^{\star}\end{array}$ & $\begin{array}{l}\text { Men with } \\
\text { diabetes (n) }\end{array}$ & Population* & $\begin{array}{l}\text { Prevalence of } \\
\text { diabetes }(\%)^{*}\end{array}$ & $\begin{array}{l}\text { Women with } \\
\text { diabetes (n) }\end{array}$ \\
\hline $25-29$ & 7312030 & 2.7 & 197467 & 7357770 & 4.2 & 308150 \\
\hline $30-34$ & 6796110 & 3.9 & 267674 & 7028330 & 5.6 & 391801 \\
\hline $45-49$ & 4626430 & 9.4 & 433997 & 4591970 & 10.5 & 482417 \\
\hline $50-54$ & 4012750 & 11.1 & 445988 & 3923260 & 11.7 & 458192 \\
\hline $55-59$ & 2962960 & 12.3 & 365906 & 2818620 & 12.3 & 345557 \\
\hline Total & 44903380 & 5.7 & 2579975 & 45003080 & 7.0 & 3153114 \\
\hline
\end{tabular}

${ }^{*}$ Age and gender-specific population estimates and age and gender-specific prevalence of diabetes based on estimates by age and gender from the International Diabetes Federation Diabetes Atlas for $2017 .{ }^{4}$ 


\begin{tabular}{|c|c|c|c|c|c|c|}
\hline Age group & $\begin{array}{l}\text { Deaths in } \\
\text { cohort with } \\
\text { diabetes }\end{array}$ & $\begin{array}{l}\text { Deaths in 'diabetes } \\
\text { cohort' assuming } \\
\text { no diabetes }\end{array}$ & $\begin{array}{l}\text { Excess deaths } \\
\text { in diabetes } \\
\text { cohort }\end{array}$ & $\begin{array}{l}\text { Years of life } \\
\text { lived in cohort } \\
\text { with diabetes }\end{array}$ & $\begin{array}{l}\text { Years of life lived } \\
\text { in 'diabetes cohort' } \\
\text { assuming no diabetes }\end{array}$ & $\begin{array}{l}\text { Years of life } \\
\text { lost (\%) }\end{array}$ \\
\hline \multicolumn{7}{|l|}{ Men } \\
\hline $20-24$ & 37880 & 14534 & 23346 & 3091579 & 3279527 & $187948(5.7)$ \\
\hline $25-29$ & 52044 & 20627 & 31417 & 3949032 & 4194217 & $245185(5.8)$ \\
\hline $30-34$ & 69329 & 28342 & 40987 & 4835772 & 5142610 & $306838(6.0)$ \\
\hline $35-39$ & 84858 & 35770 & 49088 & 5386737 & 5730419 & $343682(6.0)$ \\
\hline $40-44$ & 90752 & 39439 & 51313 & 5193160 & 5514858 & $321698(5.8)$ \\
\hline $45-49$ & 90204 & 40391 & 49813 & 4610903 & 4870686 & $259784(5.3)$ \\
\hline $50-54$ & 76201 & 35218 & 40982 & 3306543 & 3458901 & $152358(4.4)$ \\
\hline $55-59$ & 33603 & 15868 & 17735 & 1339258 & 1372462 & 33204 (2.4) \\
\hline Total & 534871 & 230189 & 304682 & 31712983 & 33563680 & $1850697(5.5)$ \\
\hline \multicolumn{7}{|l|}{ Women } \\
\hline $20-24$ & 66692 & 16794 & 49898 & 4711657 & 5035712 & $324054(6.4)$ \\
\hline $25-29$ & 85822 & 22439 & 63383 & 5575281 & 5956434 & $381153(6.4)$ \\
\hline $30-34$ & 106562 & 28845 & 77717 & 6227373 & 6653708 & $426335(6.4)$ \\
\hline $35-39$ & 119779 & 33518 & 86261 & 6133371 & 6549170 & $415799(6.3)$ \\
\hline $40-44$ & 114967 & 33217 & 81750 & 4950391 & 5275494 & $325103(6.2)$ \\
\hline $45-49$ & 103412 & 30790 & 72622 & 3432044 & 3649764 & $217720(6.0)$ \\
\hline $50-54$ & 77001 & 22168 & 54833 & 3395268 & 3397913 & $2645(0.1)$ \\
\hline $55-59$ & 31236 & 8575 & 22662 & 1696908 & 1738891 & $41982(2.4)$ \\
\hline Total & 705470 & 196345 & 509125 & 36122293 & 38257085 & $2134792(5.6)$ \\
\hline Total & 1240340 & 426534 & 813807 & 67835276 & 71820765 & 3985489 (5.5) \\
\hline
\end{tabular}

Calculation of years of life lived was modelled in life tables with a half-cycle correction and was subject to an annual discount rate of $3 \%$.

$(26.8 \%)$ and absenteeism (8.3\%). Accordingly, the majority of costs associated with productivity losses were caused by diabetes-related labour force dropout (BDT5.1 trillion or US $\$ 63.2$ billion) followed by mortality (BDT2.1 trillion or US $\$ 26.1$ billion) and absenteeism (BDT648 billion or US\$8.1 billion). The proportion of PALYs lost to diabetes-related mortality and absenteeism were higher in men $(37.0 \%$ and $10.2 \%$, respectively) than in women ( $18.0 \%$ and $6.7 \%$, respectively), while the proportion of PALYs lost to labour force dropout was higher in women $(75.2 \%)$ than in men $(52.8 \%)$.

Table 4 includes results from scenario analyses. The model was sensitive to a number of inputs such as productivity indices, diabetes-related labour force dropout, mortality risk and model assumptions including temporal trends in mortality risk and the annual discount rate. The PALYs lost due to diabetes were reduced by $5.4 \%$ and increased by $1.6 \%$, respectively, for the upper and lower uncertainty bounds of absenteeism estimate compared with the base case. At the hypothetical $25 \%$ change of diabetes-related labour force dropout, PALYs lost changed by $16.7 \%$. Applying the upper and lower bounds of $95 \%$ CI around estimates of all-cause mortality risk associated with diabetes, PALYs lost were increased by $20.5 \%$ and decreased by $8.7 \%$, respectively.

In scenario analyses, the annual reduction in population mortality risk to $2 \%$ and removal of the temporal trends in population mortality risk resulted to $\pm 1.2 \%$ change in PALYs lost. Doubling the annual GDP growth rate to $3.6 \%$ leads to an increase in the estimate of GDP lost to BDT9.0 trillion (US $\$ 112.9$ billion), while removing all temporal trends in GDP decreased the estimate of GDP lost to BDT6.6 trillion (US\$81.9 billion). Altering the annual discount rate to $5 \%$ and $1.5 \%$ corresponded to a $17.1 \%$ reduction in PALYs lost and a $17.3 \%$ increment in PALYs lost, respectively (table 4).

\section{DISCUSSION}

This study highlights that diabetes in the working age Bangladeshi population is projected to profound loss in years of life lived and productivity. Follow-up of this population until the retirement age leads to an estimated 813 807 excess deaths, and a loss of 4.0 million years of life $(5.5 \%)$ and 9.2 million PALYs $(20.4 \%)$ due to diabetes.

The productivity loss attributable to diabetes represents a combined effect of premature mortality, 
Table 3 Productivity-adjusted life years (PALY) lived in those with diabetes, and in the same cohort assuming no diabetes, over the working lifetime of the Bangladeshi population simulated from life table modelling

\begin{tabular}{|c|c|c|c|c|}
\hline Age group & $\begin{array}{l}\text { PALYs lived in cohort } \\
\text { with diabetes }\end{array}$ & $\begin{array}{l}\text { PALYs lived in 'diabetes cohort' } \\
\text { assuming no diabetes }\end{array}$ & PALYs lost (\%) & $\begin{array}{l}\text { PALYs lost per person } \\
\text { with diabetes }\end{array}$ \\
\hline \multicolumn{5}{|l|}{ Men } \\
\hline $20-24$ & 2562248 & 2972870 & $410621(13.8)$ & 2.9 \\
\hline $25-29$ & 3360764 & 3906137 & 545374 (14.0) & 2.8 \\
\hline $30-34$ & 4153176 & 4842933 & 689757 (14.2) & 2.6 \\
\hline 35-39 & 4595244 & 5379395 & $784151(14.6)$ & 2.3 \\
\hline $40-44$ & 4334462 & 5092370 & 757908 (14.9) & 2.0 \\
\hline $45-49$ & 3710326 & 4367645 & 657319 (15.0) & 1.5 \\
\hline $50-54$ & 2528227 & 2974315 & $446088(15.0)$ & 1.0 \\
\hline $55-59$ & 958753 & 1117325 & $158572(14.2)$ & 0.4 \\
\hline Total & 26203200 & 30652989 & $4449790(14.5)$ & 1.7 \\
\hline \multicolumn{5}{|l|}{ Women } \\
\hline $20-24$ & 1385921 & 1941747 & $555826(28.6)$ & 2.4 \\
\hline $25-29$ & 1691966 & 2397905 & 705939 (29.4) & 2.3 \\
\hline $30-34$ & 1887915 & 2721664 & 833749 (30.6) & 2.1 \\
\hline 35-39 & 1800839 & 2655761 & 854922 (32.2) & 1.9 \\
\hline $40-44$ & 1360367 & 2068313 & 707946 (34.2) & 1.5 \\
\hline $45-49$ & 840444 & 1339904 & 499460 (37.3) & 1.0 \\
\hline $50-54$ & 672063 & 1108213 & 436149 (39.4) & 1.0 \\
\hline $55-59$ & 389432 & 618867 & 229435 (37.1) & 0.7 \\
\hline Total & 10280947 & 14852374 & $4823427(32.5)$ & 1.5 \\
\hline Total & 36232146 & 45505363 & 9273217 (20.4) & 1.6 \\
\hline
\end{tabular}

Calculation of PALYs was modelled in life tables and subject to an annual discount rate of $3 \%$.

diabetes-related labour force dropout and absenteeism. Over the working lifespan of the diabetes cohort, higher all-cause mortality risk in those with diabetes resulted in a $5.5 \%$ reduction in years of life lived and was similar in men and women. This is consistent with the previous study conducted in India ${ }^{21}$ but is contrary to the findings of a study conducted in China, which showed a higher mortality risk among working age Chinese men than women. ${ }^{29}$ The relative impact of diabetes on years of life lost was higher among Bangladeshi younger people due to their longer working lifespan. On the other hand, the prevalence of diabetes and labour force dropout among younger age groups was lower, which highlights the importance of prevention before onset of diabetes. The literature supports that there is a strong association of mortality with duration of diabetes and diabetes complications among young Asian population. ${ }^{30}$

Traditional health economic analyses evaluate the costeffectiveness of health interventions in terms of net costs per year of life saved or quality-adjusted life year (QALY) saved, ${ }^{31}$ but they have no inherent financial value. This study shows that the loss of productivity, measured in terms of PALYs, among the working population has economic implications as it can be ascribed a financial value. The results of our modelling estimate the loss of over 9.2 million PALYs in those with diabetes, or 1.6 PALYs per person, over their working lifespan. The average number of PALYs lost per person with diabetes in Bangladesh was higher than that reported in recent studies conducted in Australia and China. ${ }^{1316}$ The retirement age for men in Bangladesh is similar to men in China but for women it is 5 years higher in China. ${ }^{13}$ Compared with Australia, a high-income country, retirement age in Bangladesh is 10 years lower in both genders, and therefore people living with diabetes in Bangladesh incurred higher productivity losses over a shorter time frame compared with the Australian population. ${ }^{16}$ This is largely due to differences in prevalence, mortality and productivity impacts which were higher in the younger Bangladeshi population than those in Australia. In addition, labour force dropout was not considered in the Australian analysis. Both of these studies highlighted the greater productivity burden borne by younger age populations with diabetes as they acquire the disease early, and thus their onset of complication occurs early. Additionally, greater productivity loss is borne by younger people as the years of life lost due to diabetes, in proportional terms, is greater for them. Our model did not account for the direct costs of diabetes and thus, if considered, the broader economic burden of diabetes in Bangladesh could be multifold higher 


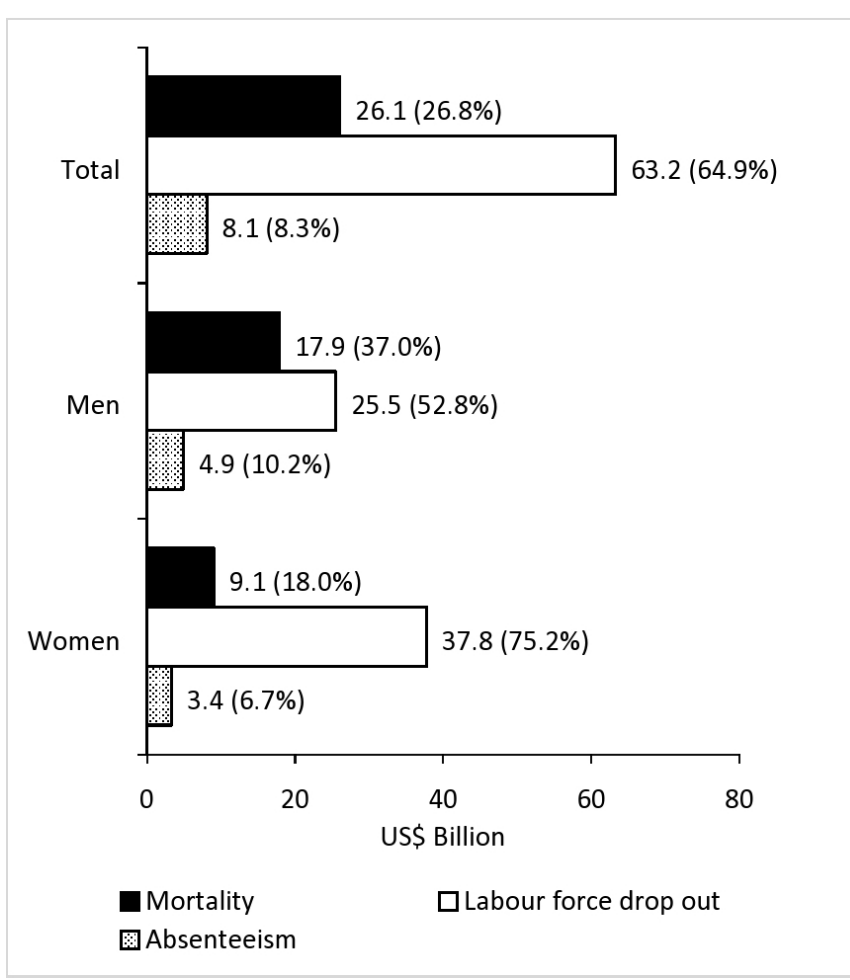

Figure 1 Economic burden of productivity loss in those with diabetes due to diabetes-related absenteeism, premature mortality and labour force dropout over the working lifespan in the Bangladeshi population.

than the current estimates, which is mirrored in previous studies. ${ }^{11} 24$

A recent study conducted in Bangladesh showed that $40 \%$ of people with type 2 diabetes had the disease before the age of 40 years. ${ }^{32}$ This study showed that the relative impact of diabetes on productivity loss was greater in younger people, which reflects the greater cumulative losses associated with early onset of diabetes. The absolute number of PALYs lost was greater in men (1.7) than in women (1.5). This may be due to the higher labour force participation of men than women in Bangladesh, ${ }^{23}$ which is related to higher diabetes-related productivity losses among men. However, the relative reduction in productivity due to diabetes was higher in women $(32.5 \%)$ than men $(14.5 \%)$, driven by higher labour force dropouts $(75.2 \%$ in women vs $52.8 \%$ in men). There is evidence of an employment shortfall in people with diabetes compared with those without diabetes. ${ }^{11} 3334$ Results from studies in the USA showed that diagnosis of diabetes was associated with approximately double the labour force participation shortfall and compared with men with diabetes, more workdays lost among women with diabetes. ${ }^{35} 36$

We estimated an average GDP loss of BDT1 358969 (US\$16 987) per person with diabetes over the working lifespan. The recent literature reports the median monthly income of Bangladeshi population is US $\$ 375,{ }^{25}$ which is equivalent to 42 months of the gross household median income. Thus, in Bangladesh, where nearly one-third $(31.5 \%)$ of the population lives below the poverty line,$^{25}$ diabetes is placing a noticeable burden on its economy. According to Islam et al, Bangladesh spends a much lower percentage $(3.5 \%)$ of its GDP on health compared with neighbouring counties like Maldives $(10.8 \%)$ or countries with similar economic status like South Africa $(8.9 \%)$ and Tanzania $(7.3 \%) .{ }^{37}$ A study conducted in Bangladesh in $2017^{25}$ showed that $3.5 \%$ of people with type 2 diabetes had income less than the estimated average annual cost of US $\$ 865$ for diabetes management. Overall, a person with type 2 diabetes in Bangladesh spent $9 \%$ of his/her annual household income on management of the disease. Acknowledging that diabetes is not $100 \%$ preventable, if even $10 \%$ of diabetes was prevented, BDT13 589 (US\$1698) could be spent per working age person as, at least, a break-even investment. This study also emphasises the importance of strengthening the current strategies on prevention of diabetes in Bangladesh.

This study quantifies the macroeconomic burden of diabetes-related productivity loss using contemporary age and sex-specific estimates of diabetes prevalence by the IDF, mortality risk and labour force participation. ${ }^{4}$ The major strength of the study is the use of PALYs to calculate productivity losses. PALYs are able to ascribe a financial value in terms of GDP and net costs. PALYs represent a useful measure alongside QALYs which require the calculation of incremental cost-effectiveness ratios $^{16}$ to estimate the impact of health interventions. Strengths of our study include the use of productivity indices stratified by age, sex and the type of work that people undertake and were sourced from a study conducted on Bangladeshi population. ${ }^{25}$ Thus, estimates of the impact of diabetes on the productivity of specific subgroups were more precise and are generalisable to the total Bangladeshi population. In addition, we used contemporary age and sex-specific estimates of diabetes prevalence, mortality risk, labour force participation and in-work productivity, which can inform the targeting of interventions. Life table modelling allowed us to capture the impact of diabetes-related productivity loss across the working age lifespan.

Life table modelling is a well-recognised tool used in epidemiological and demographic studies but is not without limitations. One limitation of this study was the mortality rates, which were estimated based on published data. The uncertainty around productivity indices was explored in sensitivity and scenario analyses and found that the model was more sensitive to variation in labour force dropout $( \pm 16.7 \%)$ while varying absenteeism by $25 \%$ had a minimum effect on estimates of PALYs lost $(+1.6 \%,-5.4 \%)$. Our model did not account for the large proportion of people $(56 \%)$ who are unaware of the presence of diabetes. ${ }^{38}$ A previous study showed that $63.4 \%$ of people with diabetes have diabetes-related complications ${ }^{32}$ but in this model an assumption was made that they are as productive as without diabetes. Thus, these results may be considered an underestimation of the 
Table 4 Sensitivity and scenario analyses to assess the impact of the uncertainties around productivity, mortality and economic data inputs on productivity-adjusted life years (PALY) lost in those with diabetes in the Bangladeshi population and the associated economic impact

\begin{tabular}{|c|c|c|c|c|}
\hline & $\begin{array}{l}\text { PALYs lost due to } \\
\text { diabetes }\end{array}$ & $\begin{array}{l}\% \text { change in PALYs lost } \\
\text { compared with base case }\end{array}$ & $\begin{array}{l}\text { GDP lost (US\$ } \\
\text { billion) }\end{array}$ & $\begin{array}{l}\text { GDP lost per person } \\
\text { with diabetes (US\$) }\end{array}$ \\
\hline Base case & 9273217 & & 97.4 & 16987 \\
\hline Productivity indices upper uncertainty bound ${ }^{\star}$ & 8773791 & -5.4 & 92.3 & 16098 \\
\hline Productivity indices lower uncertainty bound ${ }^{*}$ & 9417270 & +1.6 & 98.8 & 17241 \\
\hline $\begin{array}{l}\text { Labour force dropout upper uncertainty } \\
\text { bound } \dagger\end{array}$ & 7728881 & -16.7 & 81.8 & 14275 \\
\hline $\begin{array}{l}\text { Upper uncertainty bound of all-cause mortality } \\
\text { risk associated with diabetes } \neq\end{array}$ & 11159921 & +20.5 & 118.0 & 20574 \\
\hline $\begin{array}{l}\text { Lower uncertainty bound of all-cause mortality } \\
\text { risk associated with diabetes } \neq\end{array}$ & 8466438 & -8.7 & 88.6 & 15446 \\
\hline $\begin{array}{l}\text { Temporal trend in population mortality risk is } \\
\text { doubled to a } 2 \% \text { reduction per year§ }\end{array}$ & 9158579 & -1.2 & 96.1 & 16759 \\
\hline No temporal trend in GDPף & & & 81.9 & 14283 \\
\hline Annual discount rate increased to $5 \%$ ** & 7691123 & -17.1 & 79.0 & 13780 \\
\hline Annual discount rate reduced to $1.5 \%$ ** & 10875985 & +17.3 & 116.5 & 20313 \\
\hline
\end{tabular}

*Sensitivity analyses 1 and 2 apply (1) a 25\% reduction and (2) a 25\% increase in absenteeism estimate, holding all other model inputs constant. †Sensitivity analyses 3 and 4 apply (3) a $25 \%$ reduction and (4) a $25 \%$ increase in diabetes-related labour force dropout estimates, holding all other model inputs constant.

¥Sensitivity analyses 5 and 6 apply (5) the lower bound of the $95 \% \mathrm{Cl}$ and (6) the upper bound of the $95 \% \mathrm{Cl}$ around the estimate of relative risk of all-cause mortality associated with diabetes, holding all other model inputs constant.

§Scenario analyses 7 and 8 apply (7) double the annual reduction in mortality risk to $2 \%$ per year and (8) no temporal trend in population mortality risk, holding all other model inputs constant.

ISensitivity analyses 9 and 10 apply (9) double the annual growth rate in GDP to 3.6\% per year and (10) no temporal trend in GDP across the model, holding all other model inputs constant. These sensitivity analyses do not affect the number of PALYs lived but do affect their assumed value and therefore the resulting GDP lost.

** Sensitivity analyses 11 and 12 apply an annual discount rate (11) increased to $5 \%$ (in line with the WHO standard annual rate) and (12) reduced to $1.5 \%$.

GDP, gross domestic product.

effect of diabetes on work productivity as diabetes could still exert an impact on those with undiagnosed diabetes. We also assumed that current projections in temporal trends in mortality rates and GDP growth held true across the modelling time horizon. However, in scenario analyses, the doubling and removal of the trend in population mortality rates affected the model output by $<2 \%$, although estimates of GDP lost were more sensitive to the equivalent changes in GDP growth rate. The contribution of comorbidities of diabetes such as obesity and hypertension on productivity loss could not be distinguished from these estimates. Due to the absence of available data, an assumption was made that work will relate to paid employment and the population worked full time. Furthermore, diabetes might impact on GDP in ways other than through productivity losses. ${ }^{1012}$ While these limitations may affect the current estimates of our model, the overall conclusion of the study is unlikely to be changed.

\section{CONCLUSION}

Diabetes creates a substantial burden on the Bangladeshi population, in terms of health and well-being and lost productivity. By quantifying the economic burden of diabetes in terms of missed production opportunities, rather than health expenditure only, our findings highlight the importance of prevention, treatment and adequate control of diabetes in Bangladesh as an investment. An economic pay-off through gains in productivity can be achieved by interventions aimed to prevent and adequately control diabetes. Future studies should aim to describe the dynamics of the balance between the economic benefits arising from productivity gains and the greater investment in prevention and health services for diabetes.

\section{Twitter Zanfina Ademi @ZANFINA}

Contributors AA and TRH performed the analysis and interpretation of data. BB, DL and DJM jointly conceived the study and made a substantial contribution to the interpretation of data. EZ and ZA made a substantial contribution to the analytical strategy. AA wrote the first draft of the manuscript and TRH, EZ, AO, LC, ZA, DL, $D J M$ and $B B$ reviewed and revised the manuscript. All authors approved the final version of the article.

Funding The authors have not declared a specific grant for this research from any funding agency in the public, commercial or not-for-profit sectors.

Competing interests None declared. 
Patient and public involvement Patients and/or the public were not involved in the design, or conduct, or reporting, or dissemination plans of this research.

Patient consent for publication Not required.

Ethics approval This study was approved by the Monash University Human Research Ethics Committee (Ref No 1469) as a low-risk project.

Provenance and peer review Not commissioned; externally peer reviewed.

Data availability statement Data are available upon request. All data have been obtained from publicly available sources. AA and BB are the guarantors of this work and, as such, had full access to all the data in the study and take responsibility for the integrity of the data and the accuracy of the data analysis.

Open access This is an open access article distributed in accordance with the Creative Commons Attribution Non Commercial (CC BY-NC 4.0) license, which permits others to distribute, remix, adapt, build upon this work non-commercially, and license their derivative works on different terms, provided the original work is properly cited, appropriate credit is given, any changes made indicated, and the use is non-commercial. See: http://creativecommons.org/licenses/by-nc/4.0/.

ORCID iDs

Afsana Afroz http://orcid.org/0000-0001-7309-5280

Zanfina Ademi http://orcid.org/0000-0002-0625-3522

\section{REFERENCES}

1 Mathers CD, Loncar D. Projections of global mortality and burden of disease from 2002 to 2030. PLoS Med 2006;3:e442.

2 Shaw JE, Sicree RA, Zimmet PZ. Global estimates of the prevalence of diabetes for 2010 and 2030. Diabetes Res Clin Pract 2010;87:4-14.

3 Williams R, Colagiuri S, Almutairi R, et al. IDF diabetes atlas. Ninth edn, 2019.

4 International Diabetes Federation. IDF diabetes Atles. 8th edn. Brussels, Belgium: International Diabetes Federation, 2017

5 Ramachandran A, Ma RCW, Snehalatha C. Diabetes in Asia. Lancet 2010;375:408-18.

6 Reynolds K, Saydah SH, Isom S, et al. Mortality in youth-onset type 1 and type 2 diabetes: the search for diabetes in youth study. $J$ Diabetes Complications 2018;32:545-9.

7 Huo X, Gao L, Guo L, et al. Risk of non-fatal cardiovascular diseases in early-onset versus late-onset type 2 diabetes in China: a crosssectional study. Lancet Diabetes Endocrinol 2016;4:115-24.

$8 \mathrm{Ng}$ CS, Lee JYC, Toh MP, et al. Cost-Of-Illness studies of diabetes mellitus: a systematic review. Diabetes Res Clin Pract 2014;105:151-63.

9 Sculpher $\mathrm{M}$. The role and estimation of productivity costs in economic evaluation. In: Drummond MF, McGuire A, eds. Economic evaluation in health care: Merging theory with practice. Oxford: Oxford University Press, 2001: 94-112.

$10 \mathrm{Krol} \mathrm{M,} \mathrm{Brouwer} \mathrm{W.} \mathrm{How} \mathrm{to} \mathrm{estimate} \mathrm{productivity} \mathrm{costs} \mathrm{in} \mathrm{economic}$ evaluations. Pharmacoeconomics 2014;32:335-44.

11 American Diabetes Association. Economic costs of diabetes in the U.S. in 2017. Diabetes Care 2018;41:917-28.

12 Rasmussen B, Sweeny K, Sheehan P. The Impact of Wellness on Workforce Productivity in Global Markets. A Report to the U.S. Chamber of Commerce's Global Initiative on Health and Economy. Melbourne, Australia: Victoria Institute of Strategic Economic Studies, 2016.

13 Hird TR, Zomer E, Owen A, et al. The impact of diabetes on productivity in China. Diabetologia 2019;62:1195-203.

14 Arthur M. Institute for health metrics and evaluation. Nurs Stand 2014;28:32.
15 Cowan AJ, Allen C, Barac A, et al. Global burden of multiple myeloma: a systematic analysis for the global burden of disease study 2016. JAMA Oncol 2018;4:1221-7.

16 Magliano DJ, Martin VJ, Owen AJ, et al. The productivity burden of diabetes at a population level. Diabetes Care 2018;41:979-84.

17 Owen AJ, Maulida SB, Zomer E, et al. Productivity burden of smoking in Australia: a life table modelling study. Tob Control 2019;28:297-304.

18 Legislative and Parliamentary Affairs Division Ministry of Law, Justice and Parliamentary Affairs. The public servants (retirement) act, 1974. Available: https://www.ilo.org/dyn/natlex/docs/ELECTRONIC/14742/ 117544/F1733151744/BGD14742.pdf [Accessed 26 May 2019].

19 World Health Organization. Making choices in health: who guide to cost-effectiveness analysis, 2003.

20 GHDx. IHME-Global health data exchange (GHDx). Available: http:// ghdx.healthdata.org/ [Accessed 2 Apr 2019].

21 Anjana RM, Unnikrishnan R, Mugilan P, et al. Causes and predictors of mortality in Asian Indians with and without diabetes-10 year follow-up of the Chennai Urban Rural Epidemiology Study (CURES 150). PLoS One 2018;13:e0197376.

22 United Nations Department of Economic and Social Affairs Population Division. World population prospects: the 2017 revision, 2017.

23 International labour office. ILO labour force estimates and projections: 1990-2030. Geneve, Switzerland: International Labour Office, 2017.

24 Bommer C, Heesemann E, Sagalova V, et al. The global economic burden of diabetes in adults aged $20-79$ years: a cost-of-illness study. Lancet Diabetes Endocrinol 2017;5:423-30.

25 Afroz A, Alam K, Ali L, et al. Type 2 diabetes mellitus in Bangladesh: a prevalence based cost-of-illness study. BMC Health Serv Res 2019;19:1-12.

26 The World Bank. World development indicators, 2017. Washington D.C: The World Bank, 2018.

27 Organisation for economic co-operation and development (OECD). OECD economic outlook: statistics and projections: long-term baseline projections, real GDP long-term forecast (indicator. Paris: OECD publishing, 2018

28 Bragg F, Holmes MV, lona A, et al. Association between diabetes and cause-specific mortality in rural and urban areas of China. JAMA 2017;317:280-9.

$29 \mathrm{He}$ J, Gu D, Wu X, et al. Major causes of death among men and women in China. N Engl J Med 2005;353:1124-34.

30 Ma RCW, Chan JCN. Type 2 diabetes in East Asians: similarities and differences with populations in Europe and the United States. Ann N Y Acad Sci 2013;1281:64

31 Ademi Z, Kim H, Zomer E, et al. Overview of pharmacoeconomic modelling methods. Br J Clin Pharmacol 2013;75:944-50.

32 Afroz A, Alam K, Hossain MN, et al. Burden of macro- and microvascular complications of type 2 diabetes in Bangladesh. Diabetes Metab Syndr 2019;13:1615-22.

33 Kahn ME. Health and labor market performance: the case of diabetes. J Labor Econ 1998;16:878-99.

34 Seuring T, Archangelidi O, Suhrcke M. The economic costs of type 2 diabetes: a global systematic review. Pharmacoeconomics 2015;33:811-31.

35 Minor T, MacEwan JP. A comparison of diagnosed and undiagnosed diabetes patients and labor supply. Econ Hum Biol 2016;20:14-25.

36 Tunceli K, Bradley CJ, Nerenz D, et al. The impact of diabetes on employment and work productivity. Diabetes Care 2005;28:2662-7.

37 Islam A, Ahsan G, Biswas T. Health system financing in Bangladesh: a situation analysis. American Journal of Economics, Finance and Management 2015;1:494-502

38 Akter S, Rahman MM, Abe SK, et al. Prevalence of diabetes and prediabetes and their risk factors among Bangladeshi adults: a nationwide survey. Bull World Health Organ 2014;92:204-13. 